\title{
Early Neonatal Death
}

National Cancer Institute

\section{Source}

National Cancer Institute. Early Neonatal Death. NCI Thesaurus. Code C116772.

Death of a live newborn during the first 7 days of life. 